\title{
Potentiometric and Spectroscopic Studies on Yttrium(III) Complexes of Dihydroxybenzoic Acids
}

\author{
Rahmiye AYDIN* and Ulviye ÖZER \\ Uludă̆ University, Faculty of Arts and Sciences, Department of Chemistry; 16059-Bursa, Turkey. \\ Received July 28, 2003; accepted September 29, 2003
}

The equilibrium reactions of yttrium(III) ion with dihydroxybenzoic acids (2,3-dihydroxybenzoic acid (2,3DHBA) and 3,4-dihydroxybenzoic acid $(3,4-\mathrm{DHBA}))\left(\mathrm{H}_{3} \mathrm{~L}\right)$ were investigated in aqueous solution by means of potentiometric and spectroscopic methods, in $0.1 \mathrm{~mol} \cdot \mathrm{I}^{-1}$ ionic strength medium at $25^{\circ} \mathrm{C}$. The stability constants are reported for $\mathrm{YL}, \mathrm{YL}(\mathrm{HL})^{2-}$ and $\mathrm{YL}_{2}^{3-}-$ type mononuclear complexes. 2,3-DHBA can bind Y(III) ion strongly and the salicylate mode is effective over the acidic $\mathrm{pH}$ range. But in higher pH range, 2,3-DHBA and 3,4-DHBA act more efficiently through catecholate groups. The complexes of 2,3-DHBA are more stable than the complexes of 3,4-DHBA.

Key words stability constant; yttrium(III) ion; dihydroxybenzoic acid; potentiometric method; spectroscopic method

Yttrium is an element of the second transition series; but yttrium is always included in lanthanides. Yttrium is only in trivalent oxidation state in solution. It characteristically has a coordination number of 6 and the six coordinate radius is $1.04 \AA$ for Y(III) ion and $1.00-1.17 \AA$ for the lanthanides, although coordination numbers of $Y($ III) ion 8 and 9 are also known. ${ }^{1)}$ Yttrium as a second member of Sc, Y, La, Ac group is always found with lanthanides in nature and it also resembles very closely in its chemistry. Ionic radius of Y(III) ion is very close to the corresponding values of $\mathrm{Ho}$ (III) (1.04 $\AA$ ) and Dy(III) (1.05 $\AA$ ).

The aqua $Y($ III) ion has a strong affinity to hydroxo group itself; for that reason its complex formation equilibria are rather complicated. Either Biedermann and Ciavatta, ${ }^{2)}$ Özer ${ }^{3)}$ and Mesmer ${ }^{4)}$ reviewed the main species in aqueous solutions of Y(III) and the related equilibria constants of the hydroxo complexes. The preferences of Sc(III) and Y(III) towards catechol, salicylic acid and their derivatives were investigated by Özer and coworkers. ${ }^{5-7)}$ Thus, the hydrolytic tendencies of Y(III) ion were decreased by an increase in the number of binding sites of phenolates and or carboxylate donors.

Dihydroxybenzoic acids (DHBA) are very interesting ligands; since they have bidentate catechol part and and one carboxylate oxygen. But they were scarcely studied. ${ }^{8-22)} 3,4-$ Dihydroxybenzoic acid (3,4-DHBA), as a tribasic acid $\left(\mathrm{H}_{3} \mathrm{~L}\right)$, contains a separate carboxylate donor besides the catecholate function; it can be regarded as a catechol derivative; while 2,3-dihydroxybenzoic acid (2,3-DHBA) contains three potential binding sites on three adjacent ring carbons, only two of these groups in each ligand lose protons in the measurable $\mathrm{pH}$ range, due to the formation of intramolecular hydrogen bonds between the $-\mathrm{COO}^{-}$and phenolic $-\mathrm{OH}$ groups. It is a good model of the competitive salicylate $\left(\mathrm{CO}_{2}{ }^{-}, \mathrm{O}^{-}\right)$and catecholate type $\left(\mathrm{O}^{-}, \mathrm{O}^{-}\right)$chelation in the same molecule. $^{8,14)}$ The coordination of oxovanadium (IV) to 3,4DHBA occurs in the low $\mathrm{pH}$ range through salicylic acid donors; but the catecholate type coordination is preferred in basic media. In the case of 2,3-DHBA the stepwise deprotonation of the salicylic acid takes place and rearrangement occurs from the salicylic acid type to catechol type coordination. $^{10)}$
Martell et $a{ }^{8)}$ and Kiss et al. ${ }^{10)}$ have verified that especially 2,3-DHBA and 3,4-DHBA have affinities for metal ions to form complexes stable enough to resist their strong hydrolytic tendencies (and consequent precipitation). Martell et $a{ }^{8)}{ }^{8)}$ reviewed the acid-base chemistries of catechols, hydroxy acids, aromatic hydroxy acid anions; alkoxides, phenoxides and carboxylate ions. Then they investigated the models of coordinations in the Al(III) complexes and they determined their critical equilibria constants. While the acidbase chemistries of 2,3-DHBA and 3,4-DHBA were reviewed by Martell et l. $^{8)}$ and were measured, by potentiometry and spectroscopy by Genin ${ }^{20)}$ and Bhattacharya. ${ }^{21)}$ Some of the protonation constants of 2,3-DHBA and 3,4-DHBA were determined by Özer and coworkers earlier, ${ }^{22}$ but their affinities towards $\mathrm{Sc}(\mathrm{III})$ and $\mathrm{Y}$ (III) were not investigated so far. This paper reports the results of potentiometric and spectrophotometric studies on Y(III) complexes of 2,3-DHBA and 3,4-DHBA. Since the hydrolysis can be prevented by these two ligands and these two techniques improve the reliabilities of the investigation and the assignment of the species formed.

\section{Experimental}

Materials All the chemicals; including the Y(III) oxide, sodium hydroxide, perchloric acid, potassium hydrogen phthalate, ethylenediaminetetraacetic acid disodium salt (EDTA) and sodium perchlorate etc. used were of analytical reagent grade. Sodium hydroxide, free from carbonate, was prepared and standardized with potassium hydrogen phthalate. 2,3-DHBA and 3,4-DHBA were purchased from Sigma and Aldrich, respectively. These ligands were used without further purification; their molecular weights were periodically checked, by Gran titrations. ${ }^{23)}$ The stock solution of Y(III) was prepared, by dissolving the proper amounts of yttrium oxide (Sigma, 99.9\%) in a small excess of $\mathrm{HClO}_{4}$. Then they were standardized by EDTA titration by the method of Schwarzenbach as previously described.7) The concentrations of free acids in the Y(III) solutions were systematically checked, by potentiometric titrations before each series of experiments. All solutions were prepared in carbon dioxide free double distilled water.

Potentiometric Measurements A Schott-pH meter (Hofheim-Germany) has an accuracy \pm 0.05 and fitted with combined electrode that was calibrated with acetic acid buffer as well as with standard $\mathrm{HCl}$ and $\mathrm{NaOH}$ to give hydrogen ion concentrations directly. ${ }^{7)}$ Measurements were made at $25.0 \pm 0.05^{\circ} \mathrm{C}$ and the ionic strength was maintained at approximately $0.1 \mathrm{M}$, by the addition of $\mathrm{NaClO}_{4}$ solution to Y(III) solution, as a background electrolyte. Purified nitrogen was circulated through the jacketed titration cell under slight pressure to exclude carbon dioxide. All potentiometric titrations were carried out in triplicates. At ligand to Y(III) ratios of 2 or greater, no 
precipitation occurred; but at lower ratios of ligands the titration curves could be treated quantitatively only to $\mathrm{pH} c a$. 5.00 , as at these $\mathrm{pH}$ values a foam was first formed, which was followed by the development of a fine precipitate that will be later explained for each system. It was noticed that the increase in the number of ligands decreases the tendencies of Y(III) ion to hydrolytic reactions. Complexations were investigated within a $\mathrm{pH}$ intervals, at least $1-3$ min time intervals were necessary, between additions of successive aliquots of sodium hydroxide to reach constancy of $\mathrm{pH}$.

Spectroscopic Measurements The visible absorption spectra were taken using Shimadzu UV-2100 spectrophotometer (Kyoto, Japan) to define the existence of deprotonated ligands and complexes, at different $\mathrm{pH}$ values, as a function of wavelengths. Job's method has been applied whenever is possible. $^{23)}$

Calculations The potentiometric titration curves of these two acidic ligands and their complexes with Y(III) ions were investigated, by mathematical analysis. In order to determine the stoichiometries of possible complexes, the shapes of deprotonation and formation curves have been also deduced. For each system, the best complex that accounts for the experimental data; was accepted. Non-linear least-squares analysis of the data in terms of assumed reactions gave a satisfactory fit in the buffer regions of complexes of Y(III) with 2,3-DHBA and 3,4-DHBA systems, in different mole ratios. $\log K$ and $\log \beta$ values were obtained from related equations and were averages of at least ten calculated values in the defined regions; using RANA computer programme which was described previously. ${ }^{7)}$ The releated constants of 2,3 and 3,4-DHBA and their Y(III) complexes are listed in Table 1.

The standard deviations of the values in Table 1 were also obtained by our computer program. In order to draw the speciation diagrams, the concentrations of the species were calculated by means of RANA computer programme.

\section{Results and Discussion}

Complexes of 2,3-Dihydroxybenzoic Acid 2,3-DHBA alone and $\mathrm{Y}(\mathrm{III}): 2,3$-DHBA at $(1: 1)$ and $(1: 2)$ mole ratios were investigated potentiometrically and spectrophotometrically. The protonation constants of 2,3-DHBA have been measured earlier, ${ }^{22)}$ but the measurements were repeated ; the agreement is very good with the results of Kiss et al. ${ }^{16,19)}$ Since our values were obtained in $0.1 \mathrm{~mol} \cdot 1^{-1}$ ionic medium of $\mathrm{NaClO}_{4}$. The dissociation of $\mathrm{OH}$ group that is from 2-OH position of 2,3-DHBA; in other words, that is ortho to the carboxylate does not take place until $\mathrm{pH} c a$. 13.4, due to the strong intramolecular hydrogen bond between carboxylate $\left(\mathrm{COO}^{-}\right)$and phenol $(\mathrm{OH})$ group. On the other hand, the dissociation constant for the very weakly acidic second phenolic hydroxy group of 3,4-DHBA could be determined only with much larger uncertainty. ${ }^{16)}$ The dissociation of third phenolic $\mathrm{OH}$ could not be detected; the protonation constants of $\mathrm{L}^{3-}$ for 2,3-DHBA and 3,4-DHBA have been defined by Kiss et $a l .{ }^{16)}$; then it was introduced into the computer program to find stability constants of Y(III) complexes (Table 1).

Y(III) Complexes of 2,3-Dihydroxybenzoic Acid The potentiometric titrations were carried out in $(1: 1)$ and $(1: 2)$ mole ratios of $\mathrm{Y}$ (III) to 2,3-DHBA over the $\mathrm{pH}$ range 3.0010.00. Their titrations curves have well defined first buffers in $m=0.0-1.0$ and in $m=0.0-2.0$ ranges $(\mathrm{pH}=2.50-3.50)$ for $(1: 1)$ and $(1: 2)$ mole ratios, respectively, where $m$ represents the number of moles of base added per mole of Y(III). (Fig. 1, curve I curve II and curve III). The formation of $\mathrm{H}_{2} \mathrm{~L}^{-}$ion by dissociation of carboxyl proton between $m=0.0$ and $m=1.0$ for $(1: 1)$ mole ratio, and between $m=0.00$ and $m=2.0$ for $(1: 2)$ mole ratio may be assumed. The neutralisation curves of 2,3-DHBA $\left(\mathrm{H}_{3} \mathrm{~L}\right)$ alone and in the presence of $\mathrm{Y}(\mathrm{III})$ are superimposable in the acidic region, corresponding to the deprotonation of the carboxyl group. Since in the investigation of the chelating function of salicylic acid (SA) to Y(III) was noticed that the protonation constant of 2,3-
Table 1. Protonation Constants $(\log K)$ of Dihydroxybenzoic Acids and Stability Constants $(\log \beta)$ of Y(III) Complexes at $25.0 \pm 0.1^{\circ} \mathrm{C}$ and $I=0.1 \mathrm{~mol} \cdot 1^{-1}$

\begin{tabular}{|c|c|c|c|}
\hline Row & Equilibrium & 2,3-DHBA & 3,4-DHBA \\
\hline & Proton complexes & \multicolumn{2}{|c|}{$\log K$} \\
\hline 1 & $\begin{array}{l}\mathrm{OH}\left(\mathrm{L}^{3-}+\mathrm{H}^{+} \rightleftharpoons \mathrm{HL}^{2-}\right) \\
\mathrm{OH} \text { at 2. position in 2,3-DHBA } \\
\mathrm{OH} \text { at 3. position in 3,4-DHBA }\end{array}$ & $>14^{16), a)}$ & $13^{16), a)}$ \\
\hline \multirow[t]{2}{*}{2} & $\mathrm{OH}\left(\mathrm{HL}^{2-}+\mathrm{H}^{+} \rightleftharpoons \mathrm{H}_{2} \mathrm{~L}^{-}\right)$ & $\begin{array}{l}9.91 \pm 0.01^{22)} \\
9.81^{16), a)}\end{array}$ & $\begin{array}{l}8.66 \pm 0.01^{22)} \\
8.70^{16), a)}\end{array}$ \\
\hline & $\begin{array}{l}\mathrm{OH} \text { at 3. position in 2,3-DHBA } \\
\mathrm{OH} \text { at 4. position in 3,4-DHBA }\end{array}$ & & \\
\hline 3 & $\mathrm{COOH}\left(\mathrm{H}_{2} \mathrm{~L}^{-}+\mathrm{H}^{+} \rightleftharpoons \mathrm{H}_{3} \mathrm{~L}\right)$ & $\begin{array}{l}2.74 \pm 0.01^{22)} \\
3.32^{16), a)}\end{array}$ & $\begin{array}{l}4.26 \pm 0.01^{22)} \\
4.28^{16, a)}\end{array}$ \\
\hline & Y(III) complexes & \multicolumn{2}{|c|}{$\log \beta$} \\
\hline 4 & $\mathrm{Y}^{3+}+\mathrm{L}^{3-} \rightleftharpoons \mathrm{YL}$ & $16.09 \pm 0.04$ & $12.75 \pm 0.04$ \\
\hline 5 & $\mathrm{Y}^{3+}+\mathrm{L}^{3-}+\mathrm{HL}^{2-} \rightleftharpoons \mathrm{YL}(\mathrm{HL})^{2-}$ & $20.71 \pm 0.07$ & \\
\hline 6 & $\mathrm{Y}^{3+}+2 \mathrm{~L}^{3-} \rightleftharpoons \mathrm{YL}_{2}^{3-}$ & & $20.53 \pm 0.04$ \\
\hline
\end{tabular}

a) Protonation constants have been determined at $25.0 \pm 0.1^{\circ} \mathrm{C}$ and $I=0.20 \mathrm{~mol} \cdot 1^{-1}$ $(\mathrm{KCl})$.

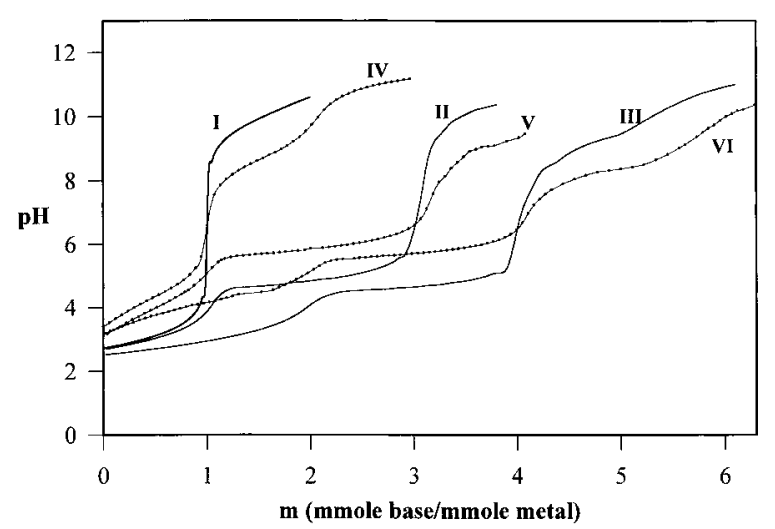

Fig. 1. Potentiometric Titration Curves of Y(III) Complexes of 2,3-DHBA and 3,4-DHBA in $0.1 \mathrm{~mol} \cdot 1^{-1}$ at $25^{\circ} \mathrm{C}$

I: 2 ,3-DHBA alone; II: $(1: 1)$ molar ratio of Y(III) to 2,3-DHBA; III: $(1: 2)$ molar ratio of Y(III) to 2,3-DHBA; IV: 3,4-DHBA alone; V: (1:1) molar ratio of Y(III) to 3,4-DHBA; VI: $(1: 2)$ molar ratio of Y(III) to 3,4-DHBA.

DHBA for $\mathrm{H}_{2} \mathrm{~L}^{-}$ion (equilibrium 3) is very close to the stability constant of $1: 1 \mathrm{Y}(\mathrm{III})$ : SA complex $(3.07 \pm 0.03)$; for that reason the anchoring action of carboxylate can be considered in this medium. Indeed the calculations have supported this assumption.

The second buffers of potentiometric titration curves were in $m=1.0-3.0$ range for $(1: 1)$ mole ratio (Fig. 1, curve II). The deprotonations of two phenol groups were assumed in $m=1.0-3.0$ range; according to equilibrium (4) (Table 1). Since the major ligand form is $\mathrm{H}_{2} \mathrm{~L}^{-}$and complexation occurs above $\mathrm{pH}=4.0$; then $\mathrm{Y}(\mathrm{III})$ coordinates $\mathrm{L}^{3-}$ ion and forms YL chelate. The formation of YL type chelate that has catecholate mode of coordination is supported by calculation. Its formation constant has been found. On the other hand, the occurrence of equilibrium (5) was considered for $(1: 2)$ $\mathrm{Y}(\mathrm{III}): 2,3$-DHBA system in second $(m=2.00-4.00)$ and third ( $m=4.0-5.0)$ buffer regions (Fig. 1, curve III), by successive deprotonations of two protons from phenol groups that are at 3. position (3-OH) of each 2,3-DHBA molecules. 


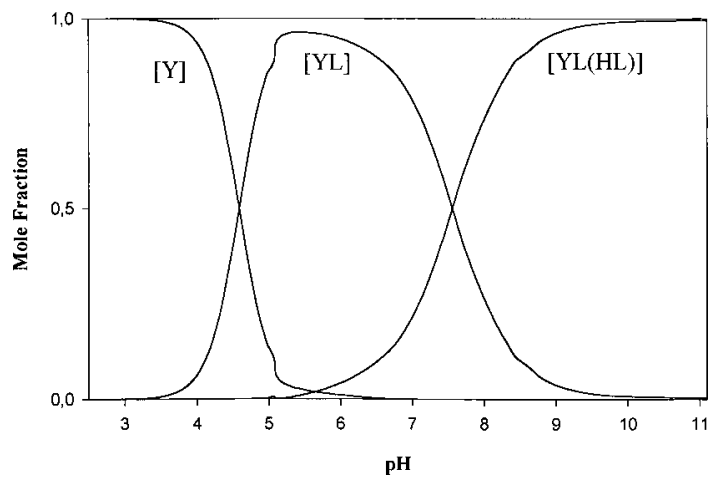

Fig. 2. Species Distribution Curves of the 2,3-DHBA System and the Metal Ion Y(III) as a Function of $-\log \left[\mathrm{H}^{+}\right]$, for a Solution Initially Containing $5.62 \times 10^{-3} \mathrm{~mol} \cdot 1^{-1} 2,3$-DHBA and $2.81 \times 10^{-3} \mathrm{~mol} \cdot 1^{-1}$ Metal Ion $T=25^{\circ} \mathrm{C}$ and $I=0.1 \mathrm{~mol} \cdot \mathrm{l}^{-1} \mathrm{NaClO}_{4}$.

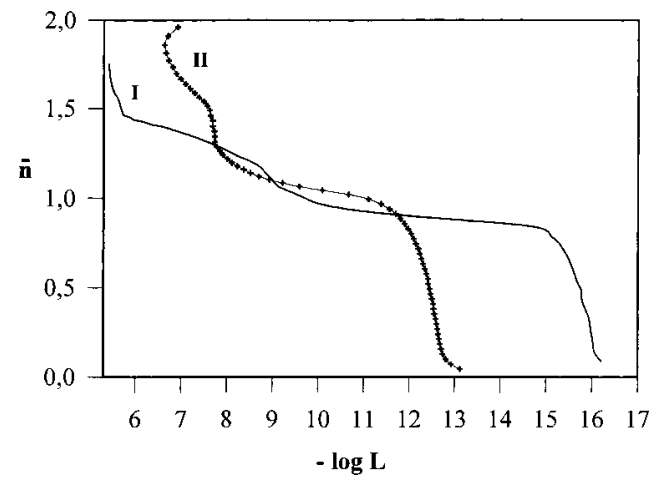

Fig. 3. Degrees of Formation for $\mathrm{Y}(\mathrm{III}): 2,3$-DHBA and $\mathrm{Y}(\mathrm{III}): 3,4-$ DHBA Systems, $n$, as a Function of $\log L$

I: Y(III) : 2,3-DHBA; II: Y(III) : 3,4-DHBA.

While third proton that was titrated in $\mathrm{pH}=8.00-9.00$ range is probably from one of the phenolic group at 2-OH position (Table 1). Thus the coordination of Y(III) to two moles of 2,3-DHBA takes place; the existence of YL(HL) ${ }^{2-}$ type coordination ion was verified by calculation. Its formation constant was determined. This strongly suggests competitive salicylate type $\left(\mathrm{COO}^{-}, \mathrm{O}^{-}\right)$coordination in acidic $\mathrm{pH}$ range, and then catecholate type $\left(\mathrm{O}^{-}, \mathrm{O}^{-}\right)$coordination in higher $\mathrm{pH}$ range. The aluminium(III) and oxovanadium(IV) ions show similar coordination abilities toward 2,3-DHBA.

The concentration distribution of assumed and then verified species were calculated from related equations; then they were drawn as a function of $-\log \left[\mathrm{H}^{+}\right]$( Fig. 2). The speciation diagrams show that the major species in defined $\mathrm{pH}$ ranges are uncoordinated $\left[\mathrm{Y}\left(\mathrm{H}_{2} \mathrm{O}\right)_{x}\right]^{3+}$ ion and $\mathrm{YL}$, YL(HL) ${ }^{2-}$ complexes in which one of 2,3-DHBA acts as a bidentate and second mole of it as a monodentate ligand.

In order to interpret the potentiometric data for Y(III) : 2,3DHBA system; the formation curves in $(1: 2)$ mole ratio were also drawn ( $-\log$ ligand concentration versus $\bar{n}$ (Fig. 3, curve I). They have one plateau at $\bar{n} \cong 1.00$ and then they reaches up to $\bar{n} \cong 1.85(\bar{n}<2)$ which suggest that $\mathrm{Y}$ (III) ion binds one mole of 2,3-DHBA in the $\mathrm{L}^{3-}$ form (equilibrium 4) but this coordination is accompanied by deprotonation of second mole of 2,3-DHBA to form (HL) ${ }^{2-}$ ion with a protonated phenol group in position 2 . and then the coordination of $(\mathrm{HL})^{2-}$ type ion to form YL(HL) $)^{2-}$ type complex. Thus in

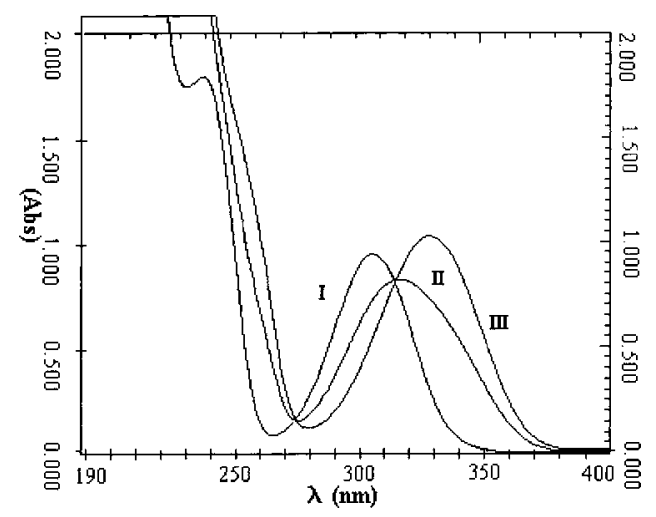

Fig. 4. Absorption Spectra of 2,3-DHBA $\left(T_{\mathrm{L}}=3.0 \times 10^{-4} \mathrm{~mol} \cdot 1^{-1}\right)$ I: $\mathrm{pH}=4.97$; II: $\mathrm{pH}=10.17$; III: $\mathrm{pH}=12.50$.

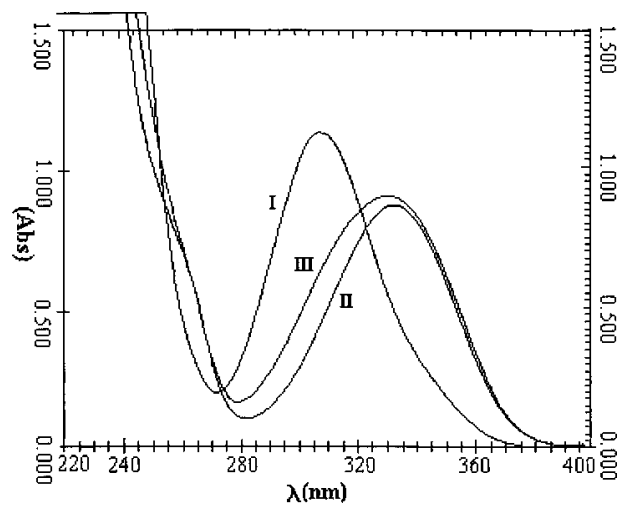

Fig. 5. Absorption Spectra of Y(III) Complexes of 2,3-DHBA in 0.1 $\mathrm{mol} \cdot 1^{-1} \mathrm{NaClO}_{4}$ at $25^{\circ} \mathrm{C}(\mathrm{pH}=9.5)$

I: 2,3 -DHBA alone $\left(T_{\mathrm{L}}=2.0 \times 10^{-4} \mathrm{~mol} \cdot 1^{-1} ; X_{\mathrm{M}}=0.0\right)$; II: $(1: 1) \mathrm{Y}(\mathrm{III}): 2,3-\mathrm{DHBA}$ $\left(T_{\mathrm{Y}}=T_{\mathrm{L}}=2.0 \times 10^{-4} \mathrm{~mol} \cdot 1^{-1} ; X_{\mathrm{M}}=0.5\right) ; \quad$ III: $\quad(1: 2) \quad \mathrm{Y}(\mathrm{III}): 2,3$-DHBA $\quad\left(T_{\mathrm{Y}}=1.34 \times\right.$ $\left.10^{-4} \mathrm{~mol} \cdot 1^{-1}, T_{\mathrm{L}}=2.68 \times 10^{-4} \mathrm{~mol} \cdot 1^{-1} ; X_{\mathrm{M}}=0.33\right)$.

$\mathrm{YL}(\mathrm{HL})^{2-}$ type complex ion the existence of $\left(\mathrm{COO}^{-}, \mathrm{O}^{-}\right)$ and $\left(\mathrm{O}^{-}, \mathrm{O}^{-}\right)$bonding modes can be suggested.

The stochiometries of formed complexes have been determined from spectroscopic results, continuous variations method was applied. ${ }^{23}$ The conformities of the 2,3-DHBA and Y(III) : 2,3-DHBA systems to Beer's Law were checked within the coordination ranges. The spectra of 2,3-DHBA at three different $\mathrm{pH}=4.97,10.17$ and 12.50 values have been taken (Fig. 4); since $\mathrm{H}_{2} \mathrm{~L}^{-}, \mathrm{HL}^{2-}$ and $\mathrm{L}^{3-}$ forms of 2,3DHBA exist in these $\mathrm{pH}$ values, respectively (Fig. 1, curve I). The maximum absorption of 2,3-DHBA solution that has $\mathrm{pH}=9.50$ value, were observed around $\lambda=305 \mathrm{~nm}$ (Fig. 5); while it has shifted to $\lambda=320 \mathrm{~nm}$ for solution of 2,3 -DHBA which is in $\mathrm{L}^{3-}$ form at $\mathrm{pH}=10.50$. From potentiometric results it was noticed that YL type coordination ion exist in $\mathrm{pH}=4.8-6.0$ range, and $\mathrm{YL}(\mathrm{HL})^{2-}$ type coordination ion occured in $\mathrm{pH}=6.8-9.2$ range. But $\mathrm{pH}$ reading have drifted around $\mathrm{pH}=5.0$ in the $1: 1 \mathrm{Y}(\mathrm{III}): 2,3$-DHBA system; it may be due to the formation and then precipitation YL complex. Therefore the application of continuous variations method was not possible in $\mathrm{pH}=4.8-6.0$ range; since the solution of $1: 1 \mathrm{Y}$ (III) :2,3-DHBA system was not clear. But the spectrum of this system in which $\mathrm{pH}$ is higher than 7.5 could be drawn; since YL(HL) ${ }^{2-}$ type complex ion was formed that is soluble in aqueous medium. Then the spectrum of the solu- 


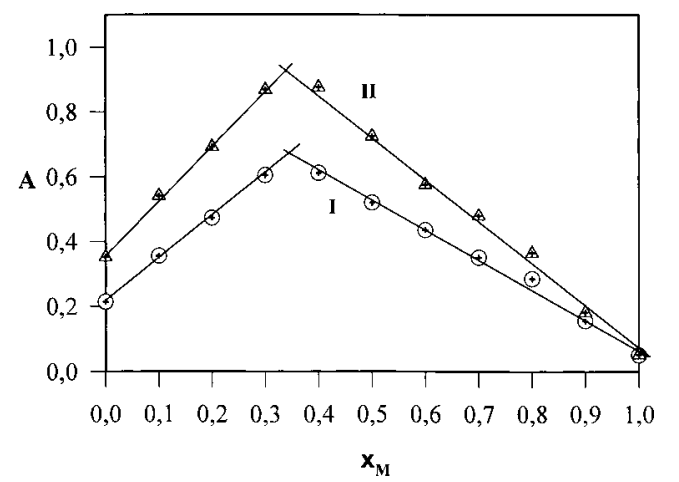

Fig. 6. Job's Plot for Y(III) Complexes

I: Y(III) : 2,3-DHBA System, $\mathrm{pH}=9.9$ at $\lambda=360 \mathrm{~nm}$; II: Y(III) : 3,4-DHBA system, $\mathrm{pH}=9.0$ at $\lambda=330 \mathrm{~nm}$.

tion was taken in which $\mathrm{Y}(\mathrm{III}): 2,3$-DHBA mole ratio was $1: 2$ and the $\mathrm{pH}$ of the solutions were 9.9 (Fig. 6). The maximum absorbances of these solutions were observed around at $\lambda=360 \mathrm{~nm}$.

Complexes of 3,4-Dihydroxybenzoic Acid Y(III) : 3,4DHBA and Sc(III) : 3,4-DHBA systems were investigated potentiometrically and spectrophotometrically at various mole ratios.

Yttrium(III) Complexes of 3,4-Dihydroxybenzoic Acid The potentiometric titrations were performed in $(1: 1)$ and $(1: 2)$ mole ratios of $\mathrm{Y}(\mathrm{III}): 3,4$-DHBA system in $0.1 \mathrm{M}$ $\mathrm{NaClO}_{4}$ ionic medium. Two inflections at $m=1.0$ and $m=3.0$, were observed for $(1: 1)$ mole ratio (Fig. 1, curve V). The potentiometric titration curves of 3,4-DHBA alone and Y(III) : 3,4-DHBA system clearly indicate that carboxyl group dissociates. Although it was verified that in $m=0.00$ 1.00 range proton from uncoordinated carboxyl has been titrated. The coordination from two phenolate oxygens that are in ortho position was assumed in $m=1.00-3.00$ range. Then stability constant of YL type chelate was defined by calculation (Table 1). In the case of $(1: 2) \mathrm{Y}(\mathrm{III}): 3,4-\mathrm{DHBA}$ system, the inflections were shifted to $m=2.0$ and to $m=4.0$ and new inflection at $m=6.0$ was also noticed (Fig. 1, curve VI). The occurrences of equilibrium (6) in $m=0.0-6.0$ range were taken into account. The constant of equilibrium (6) were determined (Table 1).

In order to verify the existences of formed $\mathrm{YL}$ and $\mathrm{YL}_{2}$ type species in Y(III) : 3,4-DHBA systems, the concentration distribution curves of the complexes versus $\mathrm{pH}$ were drawn (Fig. 7). The major species in defined $\mathrm{pH}$ range are $\left[\mathrm{Y}\left(\mathrm{H}_{2} \mathrm{O}\right)_{x}\right]^{3+}$ ion and $\mathrm{YL}, \mathrm{YL}_{2}$ complexes.

The formation curves in $(1: 2)$ mole ratio have been also drawn ( $-\log$ ligand concentration versus $\bar{n}$ (Fig. 3 , curve II). They have one plateau at $\bar{n} \cong 1.00$ and then they reaches up to $\bar{n} \cong 2.00$ which suggest that Y(III) ion binds two mole of 3,4DHBA in the $\mathrm{L}^{3-}$ form (equilibrium 6). Thus in $\mathrm{YL}_{2}^{3-}$ type complex ion the existence of $\left(\mathrm{O}^{-}, \mathrm{O}^{-}\right)$bonding modes can be suggested.

The stochiometries of formed complexes were determined from spectroscopic results. Job's method was applied, by taking UV/VIS spectra of 3,4-DHBA alone (Fig. 8) and Y(III) :3,4-DHBA system in definite mole ratios (Fig. 9). Since the spectroscopic data fitted very well with the potentiometric results. The coordination of the phenolate oxygens was clearly observed in $320-350 \mathrm{~nm}$ range, due to the

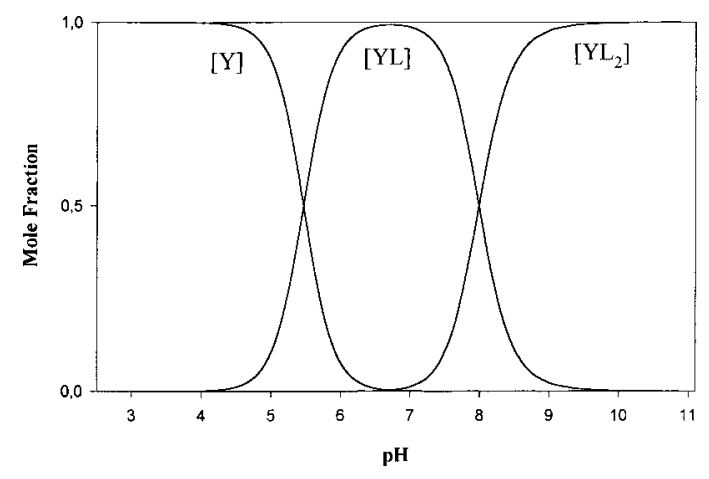

Fig. 7. Species Distribution Curves of the 3,4-DHBA System and the Metal ion Y(III) as a Function of $-\log \left[\mathrm{H}^{+}\right]$, for a Solution Initially Containing $6.98 \times 10^{-4} \mathrm{~mol} \cdot 1^{-1} 3,4$-DHBA and $3.49 \times 10^{-3} \mathrm{~mol} \cdot 1^{-1}$ Metal Ion $T=25^{\circ} \mathrm{C}$ and $I=0.1 \mathrm{~mol} \cdot 1^{-1} \mathrm{NaClO}_{4}$.

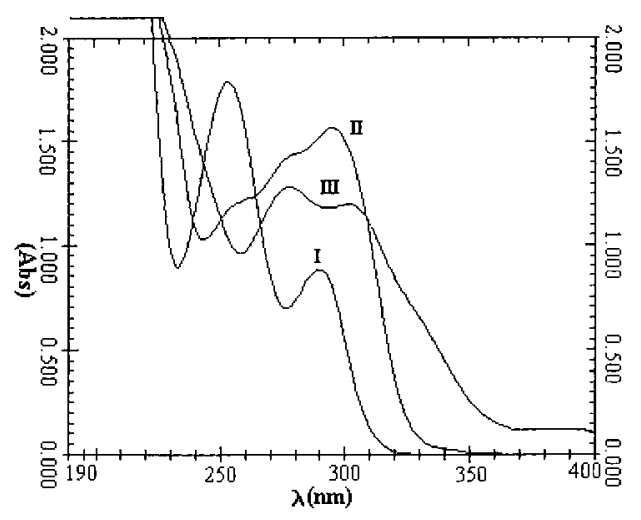

Fig. 8. Absorption Spectra of 3,4-DHBA $\left(T_{\mathrm{L}}=2.0 \times 10^{-4} \mathrm{~mol} \cdot 1^{-1}\right)$ I: $\mathrm{pH}=4.24$; II: $\mathrm{pH}=9.02$; III: $\mathrm{pH}=12.80$.

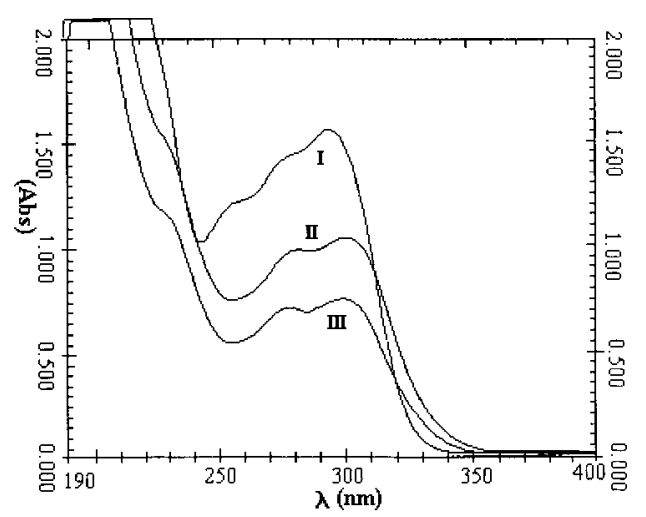

Fig. 9. Absorption Spectra of Y(III) Complexes of 3,4-DHBA in $0.1 \mathrm{~m}$ $\mathrm{NaClO}_{4}$ at $25^{\circ} \mathrm{C}(\mathrm{pH}=9.0)$

I: 3,4-DHBA alone $\left(T_{\mathrm{L}}=2.0 \times 10^{-4} \mathrm{~mol} \cdot 1^{-1} ; X_{\mathrm{M}}=0.0\right)$; II: $(1: 1) \mathrm{Y}(\mathrm{III}): 3,4$-DHBA $\left(T_{\mathrm{Y}}=T_{\mathrm{L}}=1.0 \times 10^{-4} \mathrm{~mol} \cdot 1^{-1} ; X_{\mathrm{M}}=0.5\right) ; \quad$ III: $(1: 2) \quad \mathrm{Y}(\mathrm{III}): 3,4-\mathrm{DHBA} \quad\left(T_{\mathrm{Y}}=6.60 \times\right.$ $\left.10^{-5} \mathrm{~mol} \cdot 1^{-1}, T_{\mathrm{L}}=1.32 \times 10^{-4} \mathrm{~mol} \cdot 1^{-1} ; X_{\mathrm{M}}=0.33\right)$.

charge transfer between oxygen and Y(III) ion. Then, the spectrum of $\mathrm{Y}(\mathrm{III}): 3,4-\mathrm{DHBA}$ system in $1: 1$ and $1: 2$ mole ratios at $\mathrm{pH}=9.0$ were taken in $0.1 \mathrm{M} \mathrm{NaClO}_{4}$ ionic medium. The absorbances at $330 \mathrm{~nm}$ wavelength were measured. The Job's diagram have been drawn at $\mathrm{pH}=9.0$ (Fig. 6, curve II). They indicated the existence of complex that have mole ratio $1: 2$ of Y(III) to 3,4-DHBA; thus the formation of $\mathrm{YL}_{2}^{3-}$ type complex was supported by Job's plot. 


\section{Conclusion}

The stability data of YL type complexes of 2,3-DHBA and 3,4 -DHBA reveal that the complex of 2,3-DHBA is about four orders magnitude more stable than those of 3,4-DHBA. While 2,3-DHBA with catechol structure acts more efficiently than 3,4-DHBA due to the anchoring effect of carboxyl group.

In YL type complex of 2,3-DHBA the salicylate $\left(\mathrm{CO}_{2}{ }^{-}\right.$, $\mathrm{O}^{-}$) mode is effective over the acidic $\mathrm{pH}$ range, while catecholate acts more efficiently in higher $\mathrm{pH}$ range.

Thus the coordinations of these two sides may occur according to $\mathrm{pH}$ of aqueous medium. It acts as a bidentate ligand. But in higher mole ratios like $1: 2$, the formation of YL(HL) $)^{2-}$ type occurs. Y(III) ion coordinates two moles of 2,3-DHBA through mixed bonding modes, probably it acts as bidentate and monodentate ligand.

In the case of 3,4-DHBA complexes, its coordination to Y(III) occur through different binding modes. In such a manner that 3,4-DHBA acts as a bidentate ligand via catecholate mode in $1: 1$ mole ratio and form YL type complexes. Since the carboxylate which is rather far from phenolates and can not compete with catecholate. But in $1: 2$ mole ratio, bidentate ligand action is noticed; in $\mathrm{YL}_{2}^{3-}$ type complex the coordination of $\mathrm{Y}(\mathrm{III})$ to catecholate sides $\left(\mathrm{O}^{-}, \mathrm{O}^{-}\right)$takes place.

Acknowledgements The instruments of this research were supplied by the Alexander Von Humboldt Foundation, to whom the authors wish to express their thanks.

\section{References}

1) Cotton F. A., Wilkinson G., Murillo C. A., Bochman M., "Advanced Inorganic Chemistry,” 6th ed., Wiley Interscience, New York, 1999.

2) Biederman G., Ciavatta L., Arkiv for Kemi., 22, 253-278 (1964).
3) Akalın S., Özer U. Y., J. Inorg. Nucl. Chem., 33, 4171-4180 (1971).

4) Baes C. F., Jr., Mesmer R. E., "The Hydrolysis of Cations," Wiley Interscience, New York, 1976.

5) Türkel N., Aydın R., Özer U., Tr. J. Chemistry, 23, 249-256 (1999).

6) Türkel N., Özer U., Chem. Pharm. Bull., 48, 870-872 (2000).

7) Türkel N., Aydın R., Özer U., Tr. J. Chemistry, 23, 139-152 (1999).

8) Martell A. E., Motekaitis R. J., Smith R. M., Polyhedron, 9, 171-187 (1990).

9) Smith R. M., Martell A. E., Motekaitis R. J., "NIST Critically Selected Stability Constant of Metal Complexes Database," Version 4, U.S. Department of Commerce Technology, Administration, National Instute of Standards and Technology, Standard Reference Data Program, Gaithersburg, MD 20899, 1997.

10) Jezowska M., Kozlowski H., Zubar A., Kiss T., Branca M., Micera G., Dessi A., J. Chem. Soc. Dalton. Trans., 2903-2907 (1990).

11) Mentasti E., Pelizzetti E., Saini G., J. Inorg. Nucl. Chem., 38, 785788 (1976).

12) Avdeef A., Sofen S. R., Bregante T. L., Raymond K. N., J. Amer. Chem. Soc., 100, 5362-5370 (1978).

13) Gerard C., Njomgang R., Pierrard J. C., Rimbault J., J. Chem. Res. (S), 294-295 (1987).

14) Aplincourt M., Pierrard J. C., Prudhomme J. C., Rimbault J., J. Chem. Res. (S), 10-11 (1989).

15) Kennedy J. A., Powell H. K. J., Aust. J. Chem., 38, 659-667 (1985)

16) Kiss T., Atkari K., Bojczuk M. J., Decock P., J. Coord. Chem., 29, 81-96 (1993).

17) Desroches S., Biron F., Berthon G., J. Inorganic Biochemistry, 75, 27-35 (1999).

18) Gerega K., Kiss T., Koslowski H., Micera G., Strinna Erre L., Inorg. Chim. Acta, 138, 31-34 (1987).

19) Kiss T., Koslowski H., Micera G., Strinna Erre L., Polyhedron, 8, 647-651 (1989).

20) Scharff J. P., Genin R., Anal. Chim. Acta, 78, 211-218 (1975).

21) Jejurkar C. R., Mavani I. P., Bhattacharya P. K., Indian J. Chem., 10, 1190-1192 (1972).

22) Aydın R., Özer U., Türkel N., Tr. J. Chemistry, 21, 428-436 (1997)

23) Beck M. T., Nagypal I., "Chemistry of Complex Equilibria," John Wiley, New York, 1990. 